\title{
Effect of apple pomace silage on blood parameters in Suffolk ewe
}

\author{
S Islam ${ }^{1,2 *}$, MN Islam ${ }^{2,3}$ and M Matsuzaki ${ }^{2,4}$
}

${ }^{1}$ Faculty of Veterinary Medicine and Animal Science, Bangabandhu Sheikh Mujibur Rahman Agricultural University, Salna, Gazipur-1706, Bangladesh; ${ }^{2}$ The United Graduate School of Agricultural Sciences, Iwate University, 3-18-8 Ueda, Morioka 020-8550, Iwate, Japan; ${ }^{3}$ Director, Phenix Group, House No. 39A, Road No. 8, Dhanmondi, Dhaka, Bangladesh; ${ }^{4}$ Faculty of Agriculture and Life Science, Hirosaki University, 3 Bunkyo-cho, Hirosaki, Aomori 036-8561, Japan

\begin{abstract}
The experiment was carried out to assess the effects of feeding apple pomace silage (APS) on blood parameters in Suffolk ewes. Three ewes were used in $3 \times 3$ Latin square design over three periods with three dietary treatments as hay diet, low ethanol APS (L-APS, ethanol $48.7 \mathrm{~g} \mathrm{~kg}^{-1} \mathrm{DM}$ ) diet and high ethanol APS (H-APS, ethanol $87.2 \mathrm{~g} \mathrm{~kg}^{-1} \mathrm{DM}$ ) diet. Alfalfa hay cube and APS provided half of $110 \%$ TDN requirement for APS diets. The area upper or under the curve (AUC) of plasma ethanol was greater $(P<0.01)$ in APS diets than that of hay diet and H-APS diet had grater $(P<0.01)$ AUC than that of L-APS. The AUC of plasma $\beta$-hydroxybutyrate in both APS diets were greater $(P<0.01)$ than that of hay diet. Plasma ethanol AUC was positively correlated $(P<0.05)$ with the AUCs of plasma lactate, triglyceride and glutamate oxaloacetate transaminase $(G O T)$, and negatively correlated $(P<0.05)$ with the $A \cup C$ of plasma urea nitrogen. Plasma lactate AUC was positively correlated $(P<0.05, P<0.01$, and $P<0.05$, respectively) with the AUC of free cholesterol, triglyceride and GOT, and negatively correlated $(P<0.01)$ with that of plasma urea nitrogen. The AUC of plasma $\beta$-hydroxybutyrate was negatively correlated $(P<0.01)$ with that of glucose. Finally, blood parameters examination revealed that feeding of APS lead to increase plasma ethanol, lactate, $\beta$-hydroxybutyrate and lipid components and tended to decrease glucose levels.
\end{abstract}

Key words: apple pomace silage, ethanol, lactate, $\beta$-hydroxybutyrate, glucose, Suffolk ewe

Bangladesh Animal Husbandry Association. All rights reserved.

Bang. J. Anim. Sci. 2018. 47 (2):51-60

\section{Introduction}

Agro-industrial by-products like citrus pulp, tomato pomace, grape pomace, apple pomace, etc. are residues obtained after processing of fruits, vegetable and crops which could profitably be used are available locally but are not fully exploited for feeding of livestock. There is an urgent need for processing technologies that are economic and practicable. In Japan, annually 160,000 tons (approximately) of apple pomace (AP) is generated (Takahashi and Mori, 2006) and it could be used as ruminant feed stuff (Alibes et al. 1984; Gasa et al. 1992; Taasoli and Kafilzadeh, 2008). The storage of this by-product is difficult due to its high moisture content which is $200-250 \mathrm{~g} \mathrm{DM} \mathrm{kg}^{-1}$ (Taasoli and Kafilzadeh 2008) and rich in fermentable carbohydrate with organic acid (Alibes et al. 1984). It is therefore necessary to utilize immediately or to conserve it by a process of ensiling or dehydration.
Ensiling could be one of the best methods of preserving AP and blended with other ingredients make it nutritionally balanced that could be a good feed source for ruminant (Islam et al. 2018). Ethanol is one of the most important intermediates formed during fermentation of silage and fermented feed for ruminants which was found in the previous works; such as corn silages (McDonald et al. 1991; Raun and Kristensen, 2010), grass silages (Lawrence et al. 2011), ensiled TMR (full) silages (Cummins et al. 2009), sugarcane silage (Daniel et al. 2013) and APS (full)(Islam et al. 2018, 2014a and 2014b; Kondo et al. 2010; Alibes et al. 1984). Excess alcohol intake may result in increased alcohol load in the liver (Jean-Blain et al. 1992) and followed by hours of elevated peripheral concentrations of alcohol (Kristensen et al. 2007). Alcoholic beverage consumption lowered postprandial glycaemia in human (Brand-Miller et a. 2007) which might be due to ethanol's actions of suppression of hepatic gluconeogenesis and glucose output.

*Corresponding author: shilpibsmrau@yahoo.com 
On the other hand, APS ethanol ingestion influenced decreasing the plasma glucose concentration in sheep (Kondo et al. 2011) and induced postprandial transient hyperketonemia through suppression of hepatic gluconeogenesis (Islam et al. 2014a). Evidence of APS ethanol effect on blood biochemistry is limited. Therefore, the current study was undertaken to observe the effect of different levels of APS ethanol on different blood parameters of Suffolk shorn ewes (make it homogenious in all the places. or Suffolk ewes).

\section{Materials and Methods}

Animal, experimental design and management

All animals and procedures involved in this study were approved by the Institutional Animal Care and Use Committee at Hirosaki University, Japan (A08023). Three Suffolk shorn ewes (aged 11 months on average and weighing 51.1 $\pm 1.5 \mathrm{~kg}$ ) were used in a $3 \times 3$ Latin Square Design for 21 days periods to study feeding effects of fermented APS on different blood parameters. The ewes were randomly assigned to three dietary treatments: alfalfa hay cube, alfalfa hay with low apple pomace (L-APS) and alfalfa hay with high apple pomace (H-APS) satisfying fully TDN requirement for first dietary treatment group and half of TDN requirement for the later two groups for entire experimental period including initial seven days for dietary adaptation. Daily allowance was offered as TDN requirement for $110 \%$ maintenance (Ministry of Agriculture, Forestry and Fisheries 1996; Japan) at $10 \mathrm{am}$ and $6 \mathrm{pm}$ in 2 equal meals. The required TDN amount was adjusted based on their body weight (BW). The BW was measured before the morning feeding at the beginning of each period. Ewes were housed in individual pens with sawdust bedding in an indoor animal room and had free access to a trace mineralized salt block and water throughout the experiment. According to the BW of dietary adaptation period, feed allowance was offered for the last 14 days.

\section{Apple pomace silage preparation}

Fresh apple pomace (AP) was obtained from an apple juice factory of the Farm village industry federation of Aomori prefectural agricultural cooperatives at Hirosaki, Japan. The L-APS was prepared with fresh AP mixed with soybean meal, wheat bran and beet pulp to balance TDN contents similar to a commercial concentrates (Table 1). The H-APS was prepared with fermented AP and mixed with same overall ingredients composition exception of for the different ethanol content. Because remaining sugars in fresh AP is fermented rapidly and efficiently turned into ethanol under solid-state fermentation condition (Hang et al. 1981). Fresh AP was stored alone in an anaerobic condition for 2 months to secure higher ethanol contents before ensiling of H-APS. For ensiling of L-APS, fresh AP within 2 days of production was used. The AP and all other ingredients were mixed thoroughly by a mechanical mixer and stuffed into plastic container, pressed sufficient to fill properly, topped with air-tight cover and ensiled for at least 2 months before use in the feeding experiment. Fermented components of APS were manipulated by ensiling with either fresh AP or fermented AP. Five hundred kg APS were prepared for this experiment.

Table 1: Ingredient compositions of apple pomace silages (\%, on fresh basis)

\begin{tabular}{lcc}
\hline Ingredients & L-APS $^{\mathbf{1}}$ & H-APS $^{\mathbf{2}}$ \\
\hline${ }^{1}$ Fresh AP & 70 & - \\
${ }^{2}$ Fermented AP & - & 70 \\
Soyabean meal & 6 & 6 \\
Wheat bran & 12 & 12 \\
Beet pulp & 12 & 12 \\
\hline
\end{tabular}

${ }^{1}$ Fresh AP within 2 days of production was used.

${ }^{2}$ Fermented AP was stored fresh AP for 2 months in an anaerobic condition. L-APS, low ethanol containing apple pomace silage, H-APS, high ethanol containing apple pomace silage, $\mathrm{CP}$, crude protein, TDN, total digestible nutrients.

\section{Analysis of feed and feed refusal samples}

The AP or APS extracted solution was prepared as described by Islam et al. (2014a). The extracted solution was stored at $-30^{\circ} \mathrm{C}$ for analysis of volatile basic nitrogen (VBN), organic acids and ethanol. The VBN content was determined as described by Conway (1962). Ethanol was determined by a specific gravity meter (DA-310, Kyoto Electronics, Japan) after direct distillation of the extracted sample and organic acids were analyzed by a bromotymol blue post-column method using HPLC (D-2000 HSM, Hitachi, Japan). All feed and feed refusal samples were dried in a forced-air oven at $60^{\circ} \mathrm{C}$ for 48 hours, ground through a $1 \mathrm{~mm}$ screen using a Willey mill and kept in a plastic airtight container for chemical analyses. Dry matter (DM), crude protein $(C P)$, ether extract $(E E)$, ash, crude 
fibre (CF) and organic matter (OM) were determined according to the methods of AOAC, 1990. Neutral detergent fiber (NDF) and acid detergent fiber (ADF) were determined according to the procedures of Van Soest et al. (1991). Chemical composition of experimental diets used is presented in Table 2. The $\mathrm{pH}$ value, moisture content, organic acid and other fermentation products contents and in AP and APS are presented in Table 3. Fermented AP contained the largest amount of ethanol and thus ethanol contents of L-APS and H-APS were successfully differentiated.

\section{Blood parameters and analytical methods}

On the last day of each 21 day period, series of blood samples were obtained by jugular venipuncture at pre-feeding $(0)$ and at $0.5,1,2$ and 3 hours after the morning feed. On each occasion blood was collected into two $7 \mathrm{ml}$ evacuated tube containing sodium heparin as anticoagulant, chilled on ice and centrifuged at3000 $\times \mathrm{g}$ for $15 \mathrm{~min}$ at $4{ }^{\circ} \mathrm{C}$ to harvest plasma sample. Plasma was aliquot and stored at $-30^{\circ} \mathrm{C}$ until analyzed for ethanol, lactate, $\beta$ hydroxybutyrate (BHBA) and blood metabolites [glucose, non-esterified fatty acids (NEFA), plasma urea nitrogen (UN), total cholesterol ( $T$ Cho), free cholesterol (F-Cho), high density lipoprotein cholesterol (HDL-Cho), phospholipid and triglyceride]. Another plasma aliquot was stored at $-80^{\circ} \mathrm{C}$ until the analysis for the ethanol-induced liver injury biochemical marker of glutamate oxaloacetate transaminase (GOT) and glutamate pyruvate transaminase (GPT). Plasma ethanol concentration was measured by UV method using an enzymatic F-kit ethanol kit (R-biopharma, Germany). Plasma lactate and BHBA were determined with enzymatic colorimetric methods using medical test instruments, Lactate Pro 2 (Arkray, Japan) and Precision Xceed Pro (Abbott, Japan), respectively. All plasma metabolites were determined with the enzymatic colorimetric method using Wako commercial kits (Wako pure Chemicals, Japan). Glucose was determined by using Glucose CII-test Wako, NEFA was determined by using NEFA C-test Wako, plasma UN was determined by using UN B-test Wako, T-Cho was determined by using Cholesterol E-test Wako, F-Cho was determined by using Free Cholesterol E-test Wako, HDLCho was determined by using HDL-Cholesterol E test Wako, phospholipid was determined by using Phospholipid C-test Wako and triglyceride was determined by using Triglyceride E-test Wako. Plasma GOT and GPT activities were determined with an enzymatic colorimetric method using GOT.GPT CII-test Wako (Wako, Japan).

\section{Calculation}

Hemicellulose was calculated as the difference between the NDF and ADF. Non-fibrous carbohydrate (NFC) was calculated by using the equation of NRC (2001): NFC $=100-(C P+E E$ + NDF + Ash). Ethanol intake was calculated from APS intake and ethanol contents of the APS. The area upper or under the curve (AUC) for 3 hours after feeding of plasma parameters was calculated as an indicative of the responses to feeding in each parameters.

\section{Statistical analysis}

Plasma AUC data were analyzed as a replicated $3 \times 3$ Latin square using the general linear model (GLM) procedure of SPSS, with ewe, period and diet were included in the model. Tukey test (SPSS) was used to identify differences ( $\mathrm{P}$ 0.05 ) between means. Relationship among the AUC responses for plasma measurements was analyzed by Pearson's correlation coefficient.

\section{Results}

\section{Performance traits of ewes fed different experimental diets}

No health problems were observed in any of the ewes throughout the experimental periods. Performance traits of ewes are presented in Table 3. There was no significant $(P>0.05)$ difference among the diets for ABW, MBW and total BWG. Total TDN intake $(\mathrm{kg})$ and TDN in metabolic BW $(\mathrm{kg})$ did not showed any difference among the diets. Ethanol intake was higher $(P<0.05)$ for the ewes fed on H-APS diet than that of L-APS diet whereas ewes on hay diet were not received any of alcohol.

\section{Response of area upper or under curve (AUC)}

The AUCs of plasma ethanol were greater $(P<$ 0.01 ) for APS diets than that of hay (Figure 1) and the H-APS diet had greater $(P<0.05)$ AUC than that of L-APS diet. The AUC of plasma BHBA in the both APS diets were greater than that of hay diet (Figure 1). However, there was no significant difference between the L-APS and H-APS diets for the AUC of plasma BHBA. No significant difference was observed among the diets for the AUC of plasma lactate and glucose (Figure 1). The AUC of plasma T-Cho, F-Cho, HDL-Cho, triglyceride and phospholipid did not differ among the diets (Figure 2). No significant difference was observed among the diets for the AUC of plasma NEFA, plasma UN, GOT and GPT (Figure 3). 
Table 2: Chemical composition of experimental diets ${ }^{1}$

\begin{tabular}{lccc}
\hline Item & Hay diet & L-APS diet & H-APS diet \\
\hline Dry matter (\%, fed basis) & $92.1 \pm 0.6$ & $58.2 \pm 0.3$ & $56.3 \pm 0.2$ \\
NutrientsComposition (\%DM basis) & & & \\
Organic matter & $88.5 \pm 0.2$ & $90.9 \pm 0.1$ & $90.6 \pm 0.1$ \\
Crude protein & $17.1 \pm 1.0$ & $17.1 \pm 0.5$ & $17.5 \pm 0.6$ \\
Crude fiber & $27.8 \pm 0.7$ & $21.8 \pm 0.5$ & $22.6 \pm 0.2$ \\
Ether extract & $1.8 \pm 0.2$ & $2.4 \pm 0.2$ & $2.4 \pm 0.2$ \\
Crude ash & $11.5 \pm 0.2$ & $9.1 \pm 0.1$ & $9.4 \pm 0.1$ \\
NFE & $41.8 \pm 0.8$ & $49.6 \pm 0.2$ & $48.0 \pm 0.6$ \\
ADF & $31.6 \pm 0.4$ & $27.3 \pm 0.2$ & $27.5 \pm 0.3$ \\
NDF & $46.4 \pm 0.8$ & $43.3 \pm 0.5$ & $44.9 \pm 0.5$ \\
Hemicellulose & $14.8 \pm 0.9$ & $16.0 \pm 0.5$ & $17.4 \pm 0.7$ \\
NFC & $23.2 \pm 0.6$ & $28.1 \pm 0.4$ & $25.8 \pm 0.6$ \\
\hline
\end{tabular}

${ }^{1}$ Values are means with SD of three ewes per treatment. ${ }^{2} \mathrm{NFC}=(100-\mathrm{CP}-\mathrm{EE}-\mathrm{NDF}-\mathrm{Ash}) . \mathrm{L}-\mathrm{APS}$, low ethanol containing apple pomace silage; H-APS, high ethanol containing apple pomace silage; DM, dry matter; NFE, nitrogen free extract; ADF, acid detergent fibre; NDF, neutral detergent fibre; NFC, nonfibrous carbohydrate; SD, stander deviation.

Table 3: The pH value, moisture content, organic acids and others fermented product of apple pomace and apple pomace silages

\begin{tabular}{|c|c|c|c|c|}
\hline Item & Fresh $\mathbf{A P}^{1}$ & Fermented $\mathbf{A P}^{2}$ & L-APS & H-APS \\
\hline $\mathrm{pH}$ & 4.01 & 4.08 & $3.85 \pm 0.0$ & $3.86 \pm 0.2$ \\
\hline Moisture (\%) & 76.70 & 85.69 & $63.38 \pm 6.9$ & $66.31 \pm 5.6$ \\
\hline \multicolumn{5}{|c|}{ Organic acids and other fermented products ( $\left.\mathrm{g} \mathrm{kg}^{-1} \mathrm{DM}\right)$} \\
\hline Lactic acid & 15.3 & 72.9 & $35.0 \pm 10.0$ & $36.0 \pm 22.6$ \\
\hline Acetic acid & 5.0 & 40.6 & $15.0 \pm 2.5$ & $23.6 \pm 15.0$ \\
\hline Iso-butyric acid & 0.9 & ND & ND & ND \\
\hline Butyric acid & ND & ND & ND & ND \\
\hline Propionic acid & ND & ND & ND & ND \\
\hline Total VFA ${ }^{3}$ & 5.9 & 40.6 & $15.0 \pm 2.5$ & $23.6 \pm 15.0$ \\
\hline Ethanol & 1.3 & 242.5 & $48.7 \pm 5.1$ & $87.2 \pm 14.9$ \\
\hline VBN in TN & 0.06 & 0.13 & $0.33 \pm 0.1$ & $0.65 \pm 0.3$ \\
\hline
\end{tabular}

${ }^{1}$ Fresh apple pomace within 2 days of production was used. ${ }^{2}$ Fermented AP was stored fresh AP for 2 months in an anaerobic condition. ${ }^{3}$ Total VFA $=$ (Acetic acid + Iso-butyric acid + Butyric acid + Propionic acid). ${ }^{a, b}$ Different letters indicate significant difference among the treatments (at $5 \%$ level). AP, apple pomace; L-APS, low ethanol containing apple pomace silage; H-APS, high ethanol containing apple pomace silage; DM, dry matter; ND, not detectable; VFA, volatile fatty acid; VBN, volatile basic nitrogen; TN, total nitrogen. 
Islam et al. (2018) Bang. J. Anim. Sci. 47 (2):51-60

Table 4: Performance traits of ewes fed different experimental diets ${ }^{1}$

\begin{tabular}{lcccc}
\hline Item & Hay diet & L-APS diet & H-APS diet & $\begin{array}{c}\text { Level of } \\
\text { significance }\end{array}$ \\
\hline ABW $(\mathrm{kg})$ & $52.14 \pm 2.37$ & $52.01 \pm 2.13$ & $51.40 \pm 1.44$ & 0.155 \\
MBW(kg) & $19.40 \pm 0.66$ & $19.37 \pm 0.60$ & $19.20 \pm 0.40$ & 0.154 \\
TBWG (kg for 21 days) & $0.41 \pm 1.35$ & $0.69 \pm 1.46$ & $0.69 \pm 0.22$ & 0.926 \\
Total TDNI $(\mathrm{kg})$ & $12.04 \pm 0.44$ & $12.04 \pm 0.32$ & $11.84 \pm 0.41$ & 0.358 \\
TDNIMBW(kg) & $29.56 \pm 0.42$ & $29.61 \pm 0.22$ & $29.36 \pm 0.75$ & 0.649 \\
Ethanol intake $(\mathrm{mmol} / \mathrm{d})$ & $0^{\mathrm{a}}$ & $230.14^{\mathrm{ab}} \pm 48.50$ & $327.88^{\mathrm{b}} \pm 55.39$ & 0.039 \\
\hline
\end{tabular}

${ }^{1}$ Values are means with SD of three ewes per treatment. ${ }^{2}$ Ethanol intake was calculated from the APS intake and ethanol content of the APS. ${ }^{a, b, c}$ Different letters indicate significant difference among the treatments (at 5\% level). L-APS, low ethanol containing apple pomace silage; H-APS, high ethanol containing apple pomace silage; MBW, metabolic body weight; TBWG, total body weight gain; TDNI, total digestible nutrient intake; TDNIMBW, total digestible nutrient intake in metabolic body weight; $\mathrm{mmol} / \mathrm{d}$, mile mole per day; ND, not detected; SD, stander deviation.

Table 5: Correlation coefficients among the area upper or under curve for 0-3 hours of plasma ethanol, lactate, $\beta$-hydroxybutyrate, plasma metabolites, glutamate oxaloacetate transaminase and glutamate pyruvate transaminase ${ }^{1,2}$

\begin{tabular}{lcccc}
\hline Item & Ethanol & \multicolumn{1}{l}{ Lactate } & BHBA & Glucose \\
\hline Lactate & $0.727^{*}$ & & & \\
BHBA & 0.374 & 0.374 & & \\
Glucose & -0.588 & -0.254 & $-0.915^{* *}$ & \\
T-Cho & 0.219 & 0.480 & 0.128 & -0.203 \\
F-Cho & 0.208 & $0.722^{*}$ & 0.128 & 0.077 \\
HDL-Cho & 0.196 & 0.237 & -0.304 & 0.179 \\
Triglyceride & $0.692^{*}$ & $0.861^{* *}$ & 0.659 & -0.541 \\
Phospholipid & 0.099 & -0.013 & -0.133 & 0.183 \\
Plasma UN & $-0.672^{*}$ & $-0.859^{* *}$ & -0.330 & 0.139 \\
NEFA & -0.654 & -0.347 & -0.365 & 0.244 \\
GOT & $0.682^{*}$ & $0.784 *$ & 0.501 & -0.397 \\
GPT & 0.023 & 0.405 & -0.573 & 0.651 \\
\hline
\end{tabular}

${ }^{1}$ Correlations were calculated on data sets of 9 observations. ${ }^{2}$ The asterisk indicate significantly different $(* P<0.05$ and $* * P<0.01)$. AUC, area upper or under curve; L-APS, low ethanol containing apple pomace silage; H-APS, high ethanol containing apple pomace silage; BHBA, $\beta$-hydroxybutyrate; T-Cho, total cholesterol; F-Cho, free cholesterol; HDL-Cho, high density lipoprotein cholesterol; UN, urea nitrogen; NEFA, non-esterified fatty acid; GOT, glutamate oxaloacetate transaminase; GPT, glutamate pyruvate transaminase. 
Correlation among AUC responses of plasma measurements

The correlation coefficient among the AUCs of plasma ethanol, lactate, BHBA, glucose, T-Cho, F-Cho, HDL-Cho, triglyceride, phospholipid, NEFA, plasma UN, GOT and GPT for 0-3 hours sampling windows are presented in Table 4. Plasma ethanol AUC was positively correlated ( $P$ $<0.05$ ) with the AUCs of plasma lactate, triglyceride and GOT. Plasma ethanol and lactate AUC were negatively correlated $(\mathrm{P}<$ 0.05 and $P<0.01$; respectively) with the AUC of plasma urea nitrogen. The lactate AUC was positively correlated with the AUCs of F-Cho, triglyceride and GOT $(\mathrm{P}<0.05, \mathrm{P}<0.01, \mathrm{P}<$ 0.05 , respectively). The plasma BHBA AUC was negatively correlated $(P<0.01)$ with that of the plasma glucose.

\section{Discussion}

Alcohols are normal constituents of silage and silage based rations at various concentrations, depending on the fermentation profile (Kristensen, et al. 2010). Moreover, ensiling apple pomace results in the conversion of most of the water-soluble carbohydrates into fermentation end-products (McDonald et al. 1991). Ethanol is the main fermentation endproduct in APS (Alibes et al. 1984). The fermented AP was identified as the largest ethanol content $\left(242.5 \mathrm{~g} \mathrm{~kg}^{-1}\right)$ whereas fresh AP was $13 \mathrm{~g} \mathrm{~kg}^{-1}$. It's indicated that drained fluid of H-APS were particularly rich in alcohol because L-APS contained $4.87 \%$ and H-APS contained $8.72 \%$ ethanol. Ethanol content of H-APS used in this experiment was higher than that of others (Islam et al. 2014a; Daniel et al. 2013; Lawrence et al. 2011; Raun and Kristensen 2010; Cummins et al. 2009 and McDonald et al. 1991). Any of performance traits was not affected by a difference in ethanol intake between L-APS and H-APS treatments in this experiment. Therefore, ingested dose of ethanol ( $328 \mathrm{mmol} / \mathrm{d}$ ) from APSs in this study would not cause any harmful influence on performance of growing ewes.

In ruminants, contrary to man and monogastric animals, a significant proportion of any ingested ethanol can be transformed into short chain fatty acids by rumen bacteria (Pradhan and Hemken 1970; Czerkawski and Breckenridge 1972; Durix et al. 1991) and is also immediately absorbed across the rumen epithelium (Veresegyházy et al. 2003). Moreover, ethanol can contribute up to $10 \%$ of the energy requirements but excess alcohol intake may result in increased alcohol load into the liver (Jean-Blain et al. 1992) and followed by hours of elevated peripheral concentrations of alcohol (Kristensen et al. 2007). After ingestion of APSs, plasma ethanol and BHBA concentrations were increased. Such increasing tendency has been reported by Kristensen et al. (2007) and these findings were also similar with our previous findings (Islam et al. 2014a, 2014b and 2018).

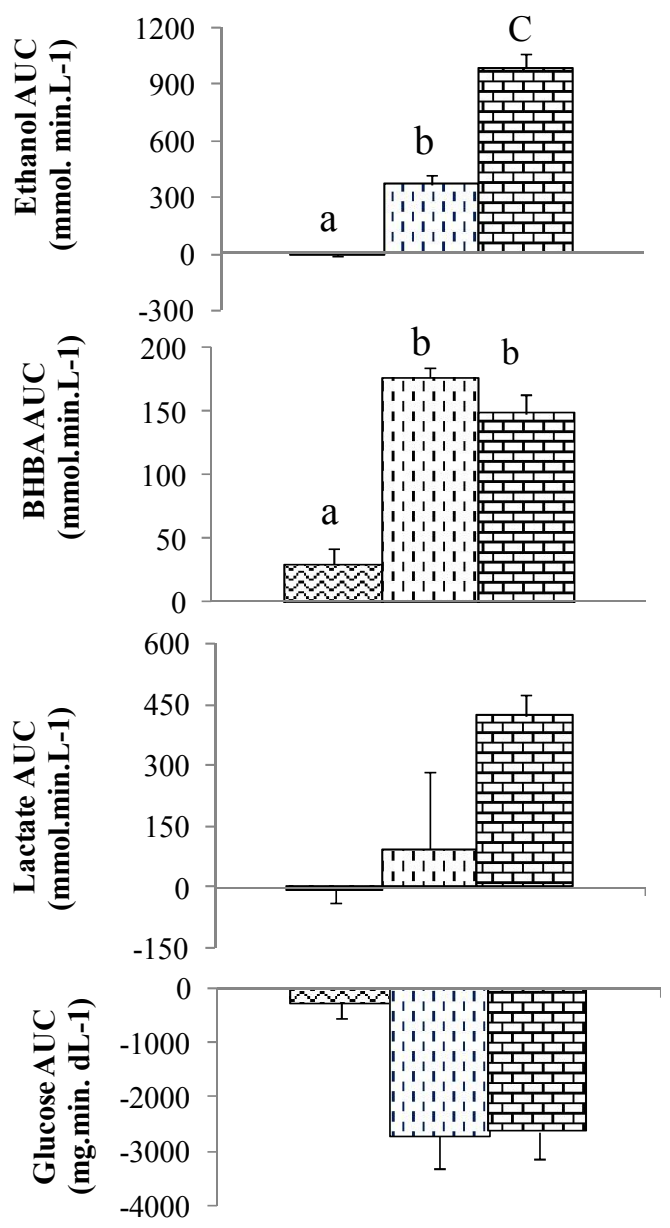

Figure 1: The area upper or under the curve (AUC) of plasma ethanol, $\beta$ hydroxybutyrate (BHBA), lactate and glucose of ewes fed on control diet (zigzag bar) or L-APS diet (dashed bar) or H-APS diet (brick bar) for 3 hours sampling windows. Each data point is the mean of 3 observations \pm standard error of the means. Different letters indicate significant difference among the diets (at $1 \%$ level) 


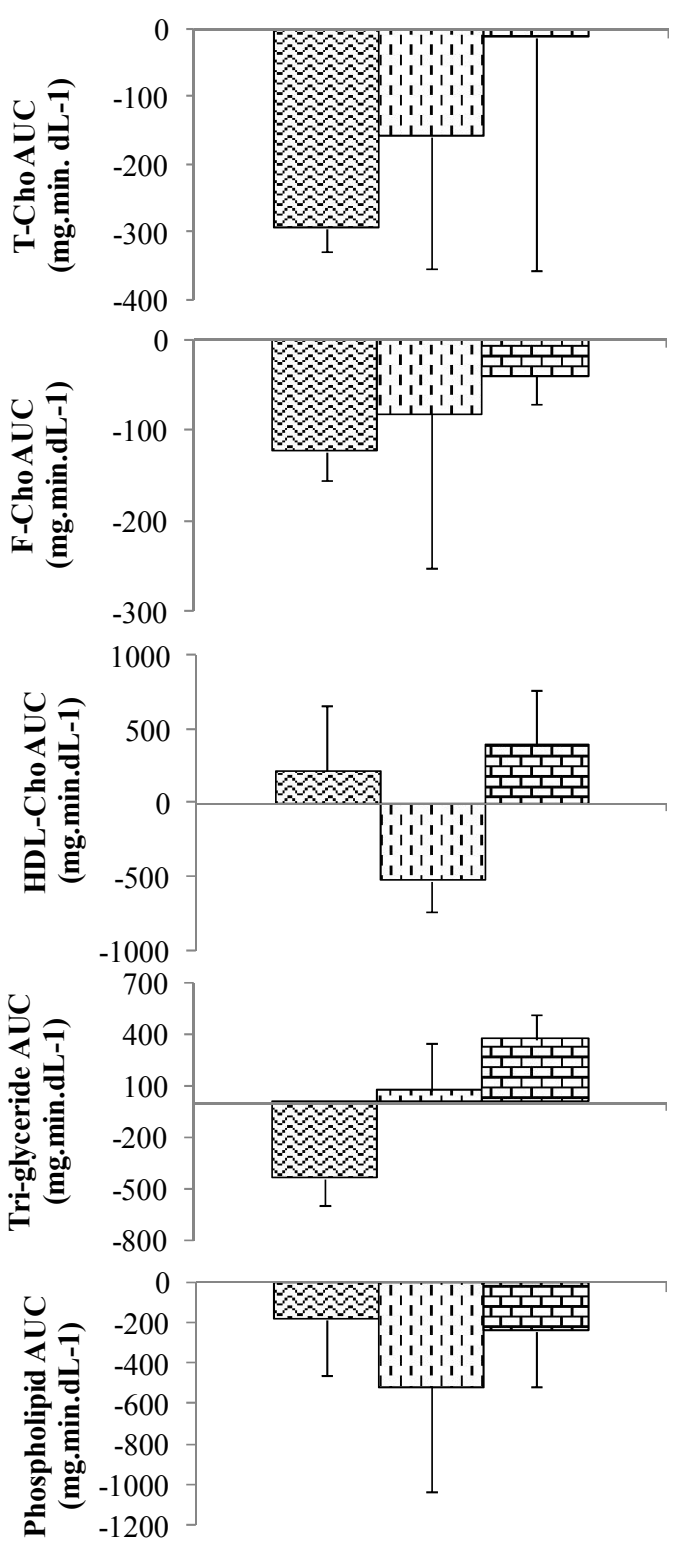

Figure 2: The area upper or under the curve (AUC) of plasma total cholesterol (TCho), free cholesterol (F-Cho), total cholesterol (T-Cho), high-density lipoprotein cholesterol (HDL-Cho), triglyceride and phospholipid of ewes fed on control diet (zigzag bar) or L-APS diet (dashed bar) or H-APS diet (brick bar) for 3 hours sampling windows. Each data point is the mean of 3observations \pm standard error of the means

The higher level of dietary ethanol ingestion significantly influenced the plasma ethanol concentration which was indicated by the greater AUC level for L-APS and H-APS. Plasma ethanol concentrations were not returned to pre-feeding levels at 3 hours after morning feeding and H-APS showed greater AUC level than that of L-APS. This corresponds with hypothesis the feeding dietary ethanol led to accumulation in plasma ethanol (Jean-Blain et al. 1992; Kristensen et al. 2007; Kondo et al. 2010, 2011; Raun and Kristensen 2011; Islam et al. 2014a, 2014b and 2018). Jean-Blain et al. (1992) reported that when daily ethanol intake was 0.2 to $1 \mathrm{~g} \mathrm{~kg}^{-1}$ BW then plasma ethanol level remains below $0.25 \mathrm{~g} / \mathrm{L}$ which supports our previous findings as ethanol intake was 0.5 to $0.9 \mathrm{~g} \mathrm{~kg}^{-1} \mathrm{BW}$ then plasma ethanol level was 0.16 to $0.2 \mathrm{~g} / \mathrm{L}$ (Islam et al. 2014a). These estimates are exceeded the level in present study because daily ethanol intake were 0.2 and $0.3 \mathrm{~g} \mathrm{~kg}^{-1} \mathrm{BW}$ and the highest plasma ethanol levels was $0.17-0.33 \mathrm{~g} / \mathrm{L}$. Higher amount of lactate accumulation is associated with the excess amounts of readily fermented carbohydrate for ruminant diets (Owens et al. 1998). The positive correlation coefficient between the AUC of plasma ethanol and lactate is strongly supporting notion for this experiment.

In ruminants, abrupt glucose supply from silage has often been shown to regulate hepatic glucose production (Kristensen et al. 2007; Plaizer et al. 2005) and the multiparous ewes and high lactating dairy cow walk a fine line between glucose underproduction and ketone body overproduction (Heitmann et al. 1987). Veenhuizen et al. (1991) also reported that in ketosis cow, hepatic in vitro gluconeogenic capacity decreased and at kitotic stage plasma BHBA increased. This relation is corresponding very well to the results of highly negative correlation between the AUC of plasma glucose and BHBA which indicating ethanol inhibited gluconeogenesis and resultant in postprandial hyperketonemia. Similar result was also found in our previous study (Isalm et al. 2014a).

Holtenius and Holtenius (1996) reported that primary factor for the ketotic state is the high demand for glucose and insufficient gluconeogenesis, which is compensated by increased ketogenesis. Consistent negative correlation of plasma UN with ethanol and lactate, negative correlation of BHBA with glucose, positive correlation of lactate with FCho and positive correlation of triglyceride with ethanol and lactate are strongly supporting these notions. Therefore, we speculated that ethanol ingestion suppressed gluconeogenesis, increased lactate, hypoglycemia occurred and BHBA may be generated from fatty acids. 


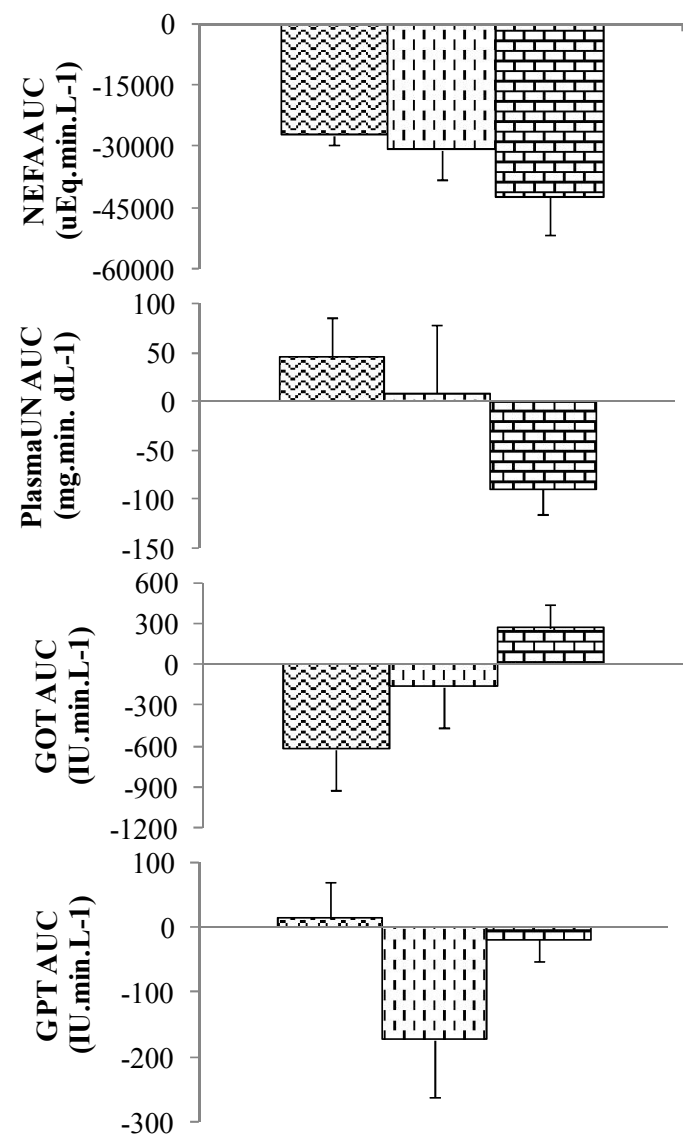

Figure 3: The area upper or under the curve (AUC) of plasma non-esterified fatty acids (NEFA), plasma urea nitrogen (UN), glutamate oxaloacetate transaminase (GOT) and glutamate pyruvate transaminase (GPT) of ewes fed on control diet (zigzag bar) or L-APS diet (dashed bar) or H-APS diet (brick bar) for 3 hours sampling windows. Each data point is the mean of 3 observations \pm standard error of the means

Although light to moderate alcohol consumption has potentially favorable effects on the cardiovascular system and potentially other tissues, excessive chronic alcohol consumption or acute intoxication adversely affects essentially all organs, ultimately increasing morbidity and mortality (Jayasekara et al. 2014). We failed to detect ethanol induce liver injury biomarker GOT and GPT but the positive correlation of plasma GOT with ethanol and lactate may indicate that higher amount of ethanol intake had a little negative effect on liver. Although all of the responses observed in blood parameters are transient in this study and no health problems were detected, need for prolonged feeding trial to assess safety and productivity of the use of APS is clearly warranted.

\section{Conclusion}

Examination of blood parameters after feeding of APS, revealed increased plasma ethanol, lactate, BHBA and lipid components and tended to decrease glucose levels. The preparation of APS with grains by products seemed to be promising, as it prevents the loss of drain fluid that are especially rich in nutrients and contains moderate concentration of fermentation end products, which is a fact of importance as far as ethanol is concerned.

\section{Acknowledgement}

The authors are gratefully acknowledged for funding the present study as a Research and development projects for application in promoting new policy of Agriculture, Forestry and Fisheries (\# 21097) from the Ministry of Agriculture, Forestry and Fisheries, Japan. We also gratefully thank to Mr. Tomoaki Saito for his help on silage organic acid analysis.

\section{References}

Alibes X, F Muñoz and J Rodriguez (1984). Feeding value of apple pomace silage for sheep. Animal Feed Science and Technology 11:189-197.

AOAC (1990). Association of Official Analytical Chemists, Official Methods of Analysis (15th ed), Arlington, VA.

Brand-Miller JC, K Fatema, C Middlemiss, M Bare, $\mathrm{V}$ Liu, $\mathrm{F}$ Atkinson and $\mathrm{P}$ Petocz (2007). Effect of alcoholic beverages on postprandial glycemia and insulinemia in lean, young, healthy adults. The American Journal of Clinical Nutrition 85: 1545-1551.

Conway EJ (1962). Microdiffusion analysis and volumetric error. 5th Edition. Crosby Lockwood, London, P. 322.

Cummins B, PO Kiely, MG Keane and DA Kenny (2009). Feed intake pattern, behavior, rumen characteristics and blood metabolites of finishing beef steers offered total mixed rations constituted at feeding or ensiling. Irish Journal of Agricultural and Food Research 48:57-73.

Czerkawski JW and G Breckenridge (1972). Fermentation of various glycolytic intermediates and other compounds by rumen microorganisms with particular 
Islam et al. (2018) Bang. J. Anim. Sci. 47 (2):51-60

reference to methane production. British Journal of Nutrition 27:131-146.

Daniel JLP, K Weiß, L Custódio, A SáNeto, MC Santos, M Zopollatto and LG Nussio (2013). Occurrence of volatile organic compounds in sugarcane silages. Animal Feed Science and Technology 185:101105.

Durix A, C Jean-Blain, HP Sallman and JP Jouany (1991). Use of a semicontinuous culture system (Rusitec) to study the metabolism of ethanol in the rumen and its effect on ruminal digestion. Canadian Journal of Animal Science 71:115-123.

Gasa J, C Castrillo, JA Guada and J Balcells (1992). Rumen digestion of ensiled apple pomace in sheep: effect of proportion in diet and source of nitrogen supplementation. Animal Feed Science and Technology 39:193-207.

Hang YD, CY Lee, EE Woodams and HJ Cooley (1981). Production of alcohol from apple pomace. Applied Environmental Microbiology 42:1128-1129.

Heitmann RN, DJ Dawes and SC Sensenig (1987). Hepatic ketogenesis and peripheral ketone body utilization in the ruminant. Journal of Nutrition 117: 1741180.

Holtenius $\mathrm{P}$ and $\mathrm{K}$ Holtenius (1996). New Aspects of Ketone Bodies in Energy Metabolism of Dairy Cows: A Review. Journal of Veterinary and Medicine 43:579-587.

Islam S, J Fang, $\mathrm{H}$ Suzuki and M Matsuzaki (2014a). Postprandial hyperketonemia after feeding of alcoholic fermented apple pomace silage in Suffolk ewes. Journal of Animal Science Advances 4(5):845-854.

Islam S, MN Islam and M Matsuzaki (2014b). Apple pomace silage ethanol intake and its effect on sheep. Bangladesh Journal of Animal Science 43(3):224-231.

Islam S, MN Islam and M Matsuzaki (2018). Nutritive value of fermented apple pomace silage and its effect in Suffolk ewes. Journal of Agricultural Science and Food Technology 4(4):80-91.

Jayasekara H, DR English, R Room and RJ MacInnis (2014). Alcohol Consumption over time and risk of death: A systematic review and meat-analysis. American Journal of Epidemiology 179:1049-1059.

Jean-Blain C, A Durix and B Tranchant (1992). Kinetics of ethanol metabolism in sheep. Reproductive Nutrition Development 32:83-90.

Kondo M, H Moriuchi, J Fang, H Suzuki and M Matsuzaki (2011). Postprandial hypoglycemia after feeding of alcohol- fermented apple pomace silage (abstract). $2011 \quad$ ADAS $\otimes$ ASAS join annual meeting abstract; Ruminant Nutrition: Ruminal Metabolism, W391.

Kondo M, F Wang, A Kimura, R Ogasawara, J Fang, H Suzuki and M Matsuzaki (2010). The decrease in blood glucose after feeding of alcohol-fermented apple pomace silage in Suffolk sheep. Japan Journal of Sheep Science 47:13-19.

Kristensen NB, KH Sloth, O Højberg, NH Spliid, $C$ Jensen and $\mathrm{R}$ Thøgersen (2010). Effects of microbial inoculants on corn silage fermentation, microbial contents, aerobic stability, and milk production under field conditions. Journal of Dairy Science 93:3764-3774.

Kristensen NB, A Storm, BML Raun, BA Røjen and DL Harmon (2007). Metabolism of silage alcohols in lactating dairy cows. Journal of Dairy Science 90:1364-1377.

Lawrence P, DA Kenny, B Earley, DH Crews Jr and M McGee (2011). Grass silage intake, rumen and blood variables, ultrasonic and body measurements, feeding behaviour and activity in pregnant beef heifers differing in phenotypic residual feed intake. Journal of Animal Science 89:3248-3261.

McDonald P, N Henderson and S Heron (1991). The Biochemistry of Silage. 2nd edition. Chalcombe Publications, Bucks, UK.

Ministry of Agriculture, Forestry and Fisheries (1996). Japanese Feeding Standard for Sheep. Tokyo, Japan.

NRC (2001). National Research Council. Nutrient Requirements of Dairy Cattle. 7th edition. National Academy Press, Washington, D.C.

Owens FN, WJ Hill and DR Gill (1998). Acidosis in cattle: A review. Journal of Animal Science 76:275-286.

Plaizier JC, AM Fairfield, PA Azevedo, A Nikkhah, TF Duffield, GH Crow, R Bagg, P Dick and BW McBride (2005). Effects of monensin and stage of lactation on variation of blood metabolites within twenty-four hours in dairy cows. Journal of Dairy Science 88:3595-3602.

Pradhan K and RW Hemken (1970). Utilization of ethanol and its effects on fatty acids patterns in ruminants. Journal of Dairy Science 53:1739-1746.

Raun BML and NB Kristensen (2010). Propanol in maize silage at Danish dairy farms. Acta Agriculturae Scandinavica, Section A-Animal Science 60:53-59.

Taasoli G and F Kafilzadeh (2008). Effects of dried and ensiled apple pomace from puree making on performance of finishing 
lambs. Pakistan Journal of Biological Science 11:294-297.

Takahashi J and T Mori (2006). Hydrogen Production from reaction of apple pomace with water over commercial steam reforming $\mathrm{Ni}$ catalysts. Journal of the Japan Petroleum Institute 49:262-267.

Van Soest PJ, JB Robertson and BA Lewis (1991). Methods for dietary fiber, Neutral detergent fiber and nonstarch polysaccharides in relation to animal nutrition. Journal of Dairy Science 74:3583-3597.
Veenhuizen JJ, JK Drackley, MJ Richard, TP Sanderson, LD Miller and JW Young (1991). Metabolic changes in blood and liver during development and early treatment of experimental fatty liver and ketosis in cows. Journal of Dairy Science 74(12):4238-4253.

Veresegyházy T, H Febel, G Nagy and A Rimanoczy (2003). .Disappearance of ethanol from isolated sheep rumen. Acta Veterinaria Hungarica 51:189-196. 